\title{
Calendrier des activités (de juillet 2011 à juin 2012)
}

\section{(2) OpenEdition}

10 Journals

Édition électronique

URL : https://journals.openedition.org/cem/12111

DOI : $10.4000 / \mathrm{cem} .12111$

ISSN : 1954-3093

\section{Éditeur}

Centre d'études médiévales Saint-Germain d'Auxerre

\section{Édition imprimée}

Pagination : 7

ISSN : 1623-5770

Référence électronique

"Calendrier des activités (de juillet 2011 à juin 2012) », Bulletin du centre d'études médiévales d'Auxerre / BUCEMA [En ligne], 15 | 2011, mis en ligne le 16 décembre 2011, consulté le 22 septembre 2022. URL : http://journals.openedition.org/cem/12111; DOI : https://doi.org/10.4000/cem.12111

Ce document a été généré automatiquement le 22 septembre 2022.

\section{(c) (i) (2)(2)}

Creative Commons - Attribution - Pas d'Utilisation Commerciale - Partage dans les Mêmes Conditions 4.0 International - CC BY-NC-SA 4.0

https://creativecommons.org/licenses/by-nc-sa/4.0/ 


\section{Calendrier des activités (de juillet 2011 à juin 2012)}

Année 2011

\begin{tabular}{|c|c|}
\hline $\begin{array}{l}20-21 \\
\text { septembre }\end{array}$ & $\begin{array}{l}\text { Auxerre - Atelier Eginhard : Vie de Charlemagne. } \\
\text { Michel SOT et Christiane VEYRARD-COSME }\end{array}$ \\
\hline $\begin{array}{l}20-21 \\
\text { octobre }\end{array}$ & $\begin{array}{l}\text { Dijon - Élaborer un vocabulaire historique du vêtement et des textiles dans le } \\
\text { cadre d'un réseau interdisciplinaire. } \\
\text { Sophie JOLIVET }\end{array}$ \\
\hline $\begin{array}{l}\text { 3-5 } \\
\text { novembre }\end{array}$ & $\begin{array}{l}\text { Clermont-Ferrand - Mausolées et églises, } \mathrm{IV}^{\mathrm{e}} \text {-VIII }{ }^{\mathrm{e}} \text { siècle. } \\
\text { Pascale CHEVALIER et Christian SAPIN }\end{array}$ \\
\hline 18 novembre & $\begin{array}{l}\text { Luxeuil-les-Bains - Actualité de la recherche sur le «monachisme luxovien »: } \\
\text { conditions de fondations des premiers monastères et topographie. } \\
\text { Sébastien BULLY et Christian SAPIN }\end{array}$ \\
\hline $\begin{array}{l}24-25 \\
\text { novembre }\end{array}$ & $\begin{array}{l}\text { Auxerre - L'église entre la loi et la règle. } \\
\text { Dominique IOGNA-PRAT etAlain RAUWEL }\end{array}$ \\
\hline
\end{tabular}

\section{Année 2012}

27 janvier

Dijon- CBMA-Chartae Burgundiae Medii Aevi- VI. Les chartes bourguignonnes sous Philologic. Eliana MAGNANI et Marie-José GASSE-GRANDJEAN 


\begin{tabular}{|l|l|}
\hline 4-6 avril & $\begin{array}{l}\text { Glux-en-Glenne - Les oiseaux chanteurs. Sciences, pratiques sociales et } \\
\text { représentations en Europe du Moyen Âge à nos jours. } \\
\text { Corinne BECK et Martine CLOUZOT }\end{array}$ \\
\hline 5-6 avril & $\begin{array}{l}\text { Baume-les-Messieurs- Journées d'études monas-tiques. Autour du cloitre : les } \\
\text { chapelles Notre-Dame et les accès au chapitre. } \\
\text { Sébastien BULLY etChristian SAPIN }\end{array}$ \\
\hline $\begin{array}{l}\text { 11-12 mai } \\
\text { (report au } \\
\text { 12-13 oct.) }\end{array}$ & $\begin{array}{l}\text { Auxerre - Les « sols construits ». } \\
\text { Christian SAPIN et Jean-Jacques SCHWIEN }\end{array}$ \\
\hline 24-27 mai & $\begin{array}{l}\text { Osor (île de Cres), Croatie- Le monachisme insulaire du IV à la fin du XI siècle. } \\
\text { Sébastien BULLY, Miljenko JURKOvić et Christian SAPIN }\end{array}$ \\
\hline 28-29 juin & $\begin{array}{l}\text { Auxerre- De Cluny à Auxerre, par la voie des « émotions ». Un parcours } \\
\text { Dominique IOGNA-PRAT }\end{array}$ \\
\hline
\end{tabular}

